\title{
Celiac disease: Diagnosis at laparoscopy
}

\author{
Guido MA Van Rosendaal MD, Walley J Temple MD
}

\begin{abstract}
GMA Van Rosendaal, WJ Temple. Celiac disease: Diagnosis at laparoscopy. Can J Gastroenterol 2004;18(2):107-108.

A 27-year-old woman was found to have an abnormal small bowel at the time of an elective laparoscopic tubal ligation. Subsequent investigation revealed celiac disease to be the underyling cause. The changes identified are believed to reflect an increased intestinal blood flow, which has been identified in the diagnostic imaging literature to be associated with active celiac disease. Further study of this feature of celiac disease may provide additional insights into its pathophysiology.
\end{abstract}

Key Words: Celiac disease; Laparotomy; Mesenteric circulation

\section{La maladie coliaque : Un diagnostic par laparoscopie}

On a découvert qu'une femme de 27 ans présentait un intestin grêle anormal au moment d'une ligature des trompes non urgente effectuée par laparoscopie. Les explorations subséquentes ont révélé qu'une maladie cœliaque en était la cause sous-jacente. On pense que les modifications dépistées reflètent un débit sanguin intestinal accru qui, selon la documentation scientifique reliée à l'imagerie diagnostique, s'associe à une maladie cœliaque active. Une étude plus approfondie de cette caractéristique de la maladie cœliaque pourrait fournir de nouvelles connaissances sur sa physiopathologie.
$\mathrm{T}$ he clinical presentation of celiac disease includes several common and a number of unusual presentations. The present case falls into the latter category, and the authors discuss the features that highlight aspects of the pathophysiology of this disease that have received little attention in the literature.

\section{CASE PRESENTATION}

A 27-year-old woman with a 10-year history of uncomplicated type 1 diabetes was referred for a tubal ligation. Evaluation in the preoperative assessment clinic revealed gastroesophageal reflux for which she took Tums (GlaxoSmithKline, USA); no other gastrointestinal symptoms were noted. Abdominal examination was normal.

At laparoscopy the small bowel was found to be grossly abnormal with circumferential erythema, dilated blood vessels and lacteals (Figure 1). Interoperative consultation with general surgery was obtained and she was subsequently referred for gastroenterology consultation.

Further functional inquiry confirmed the use of Tums for vague abdominal discomfort. She had a tendency to constipation and reported occasional episodes of abdominal bloating and borborygmi. Her weight had fallen by $6.5 \mathrm{~kg}$ over the previous year despite a normal food intake.

Small bowel radiography was normal and at endoscopy 'scalloping' was seen in the proximal small bowel. The immunoglobulin $\mathrm{G}$ antiendomysial antibody titre was positive to $1: 1280$ (normal less than 1:2.5) and the lactulose/mannitol ratio was increased to 0.092 (normal less than 0.025 ). Severe villous atrophy, crypt hyperplasia and inflammatory infiltrate consistent with celiac disease was seen in the histopathology of the duodenum (Figure 2). Bone densitometry revealed osteopenia.

At follow-up one month following initiation of a glutenfree diet, she felt well. Management of her diabetes had become somewhat more problematic because of a rise in her blood glucose levels and her abdominal discomfort had improved. She did not return for follow-up evaluation after six to nine months, as recommended, and was subsequently interviewed by telephone. This revealed that, initially, on gluten restriction she had considerable difficulty controlling her diabetes and experienced a gain in weight from $44.5 \mathrm{~kg}$ to $50 \mathrm{~kg}$. She continues to be free of gastrointestinal symptoms 18 months following initiation of a gluten-free diet.

\section{DISCUSSION}

We tend to think of gluten-sensitive enteropathy as a disease of the small bowel mucosa, and we focus our attention on the underlying immunological events, the histopathology and the functional consequences of the changes to the intestinal mucosa $(1,2)$. However, as confirmed by this case, there is more extensive involvement of small bowel that include substantial changes to intestinal blood flow. Several studies using angiography and/or Doppler ultrasound have shown an increase in mesenteric blood flow in celiac disease in both adults and children (3-8). This increase varies directly with disease activity and normalizes with treatment. It has been speculated that the release of inflammatory mediators in the intestinal mucosa, local hormonal and nutrient factors as well

Departments of Community Health Sciences and Medicine, Faculty of Medicine, University of Calgary, Health Sciences Centre, Calgary, Alberta Correspondence: Dr Guido Van Rosendaal, The University of Calgary, Faculty of Medicine, Departments of Community Health Sciences and Medicine, Health Sciences Centre, 3330 Hospital Drive Northwest, Calgary, Alberta T2N4N1. Telephone 403-210-9373,

fax 403-270-7307, e-mail gurosend@ucalgary.ca

Received for publication July 29, 2003. Accepted November 12, 2003 


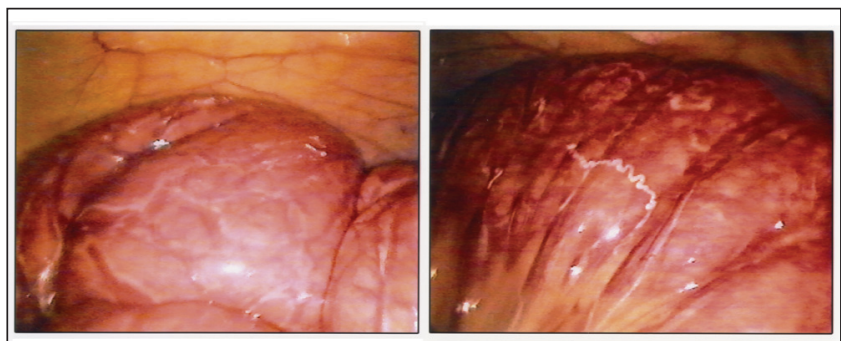

Figure 1) Appearance of small bowel from a video recording taken at laparoscopy, demonstrating vascular and lymphatic dilatation

as changes in the microcirculation that result in mucosal shunting, contribute to a hyperdynamic mesenteric circulation $(3,4)$. The systemic hypotension that is commonly observed in active celiac disease (9) may occur as a consequence of mesenteric redistribution of blood flow, or perhaps common factors underlie both cardiovascular changes.

The diagnosis of unsuspected celiac disease at abdominal surgery is likely to remain an interesting and remarkable occurrence. Further investigation of the mechanism and effect of these vascular changes may yield useful insights into the pathophysiology of this disorder.

\section{REFERENCES}

1. Farrell RJ, Kelly CP. Celiac sprue and refractory sprue. In: Feldman M, Friedman LS, Sleisenger MH, eds. Sleisenger and Fordtran's Gastrointestinal and Liver Disease 7th edn. Philadelphia: Saunders, 2002:1817-41

2. Ciclitira PJ. Celiac sisease. In: Yamada T, Alpers DH, Laine L, et al, eds. Textbook of Gastroenterology. Philadelphia: Lipincot, 1999:1660-74.

3. Alvarez D, Vazquez H, Bai JC, Mastai R, Flores D, Boerr L. Superior mesenteric artery blood flow in celiac disease. Dig Dis Sci 1993;38:1175-82.

4. Arienti V, Califano C, Brusco G, et al. Doppler ultrasonographic evaluation of splanchnic blood flow in coeliac disease. Gut 1996;39:369-73.

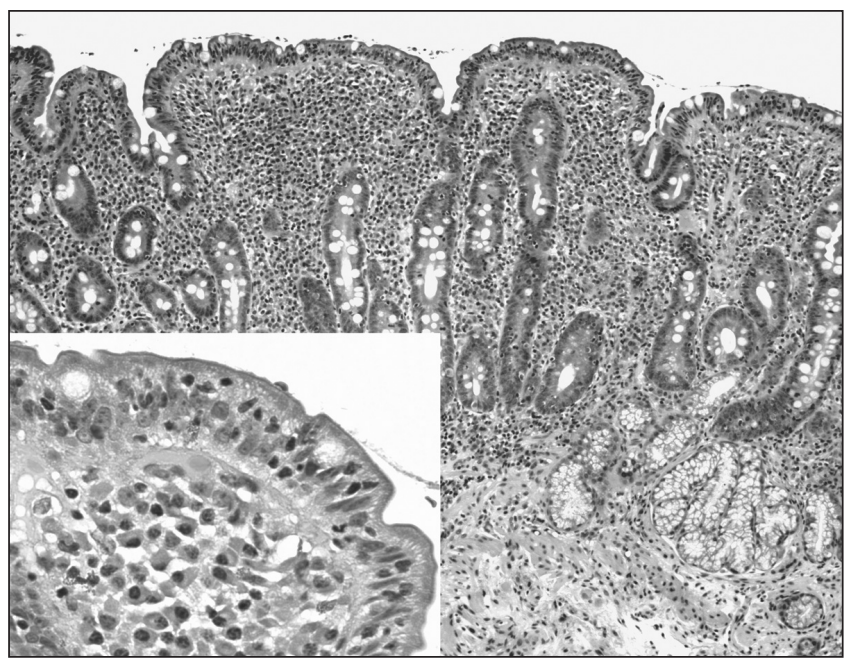

Figure 2) Photomicrograph of small bowel demonstrating villous atrophy, crypt hyperplasia and an inflammatory infiltrate with prominent intraepithelial lymphocytosis (inset)

ACKNOWLEDGEMENT: We are grateful to Dr Vincent Falck for his review of the histopathology and preparation of the photomicrograph of small bowel mucosa.

5. Bolondi L, Li BS, Gaiani S, Zironi G, Paparo GF, Barbara L. Changes in mesenteric venous flow due to celiac sprue. Dig Dis Sci 1992;37:925-8.

6. Ertem D, Tuney D, Baloglu H, Pehlivanoglu E. Superior mesenteric artery blood flow in children with celiac disease. J Pediatr Gastroenterol Nutr 1998;26:140-5.

7. Gustafson T, Sjolund K, Berg NO. Intestinal circulation in coeliac disease: An angiographic study. Scand J Gastroenterol 1982;17:881-5.

8. Giovagnorio F, Picarelli A, Di Giovambattista F, Mastracchio A. Evaluation with Doppler sonography of mesenteric blood flow in celiac disease. Am J Roentgenol 1998;171:629-32.

9. Cooke WT, Holmes GKT. Coeliac Disease. Edinburgh: Churchill Livingstone, 1984. 


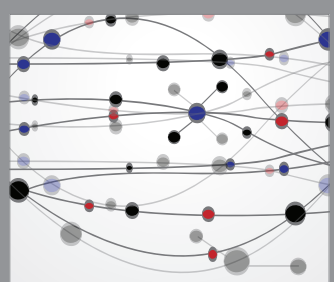

The Scientific World Journal
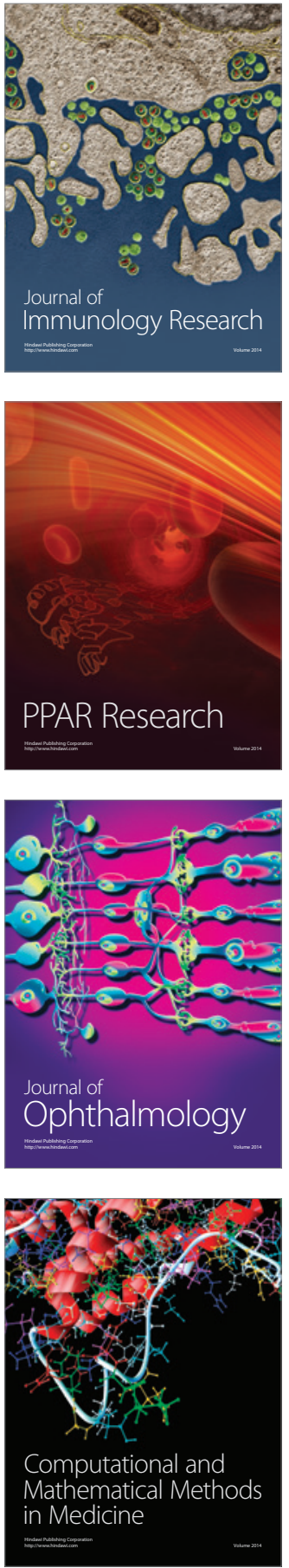

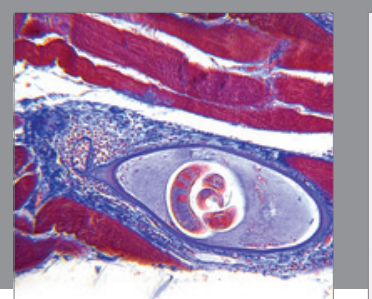

Gastroenterology Research and Practice

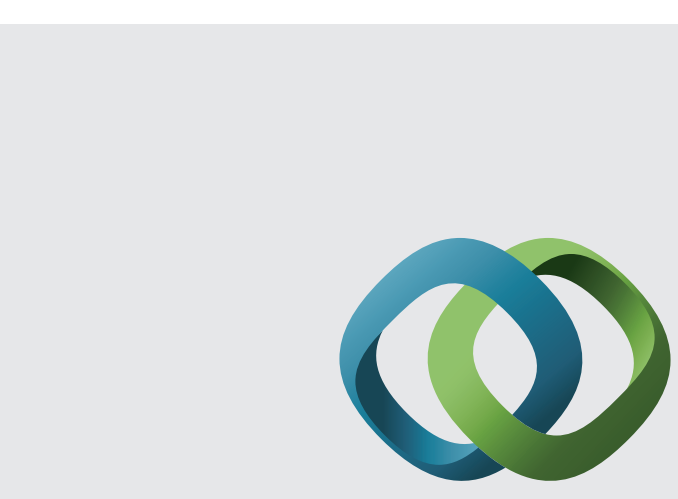

\section{Hindawi}

Submit your manuscripts at

http://www.hindawi.com
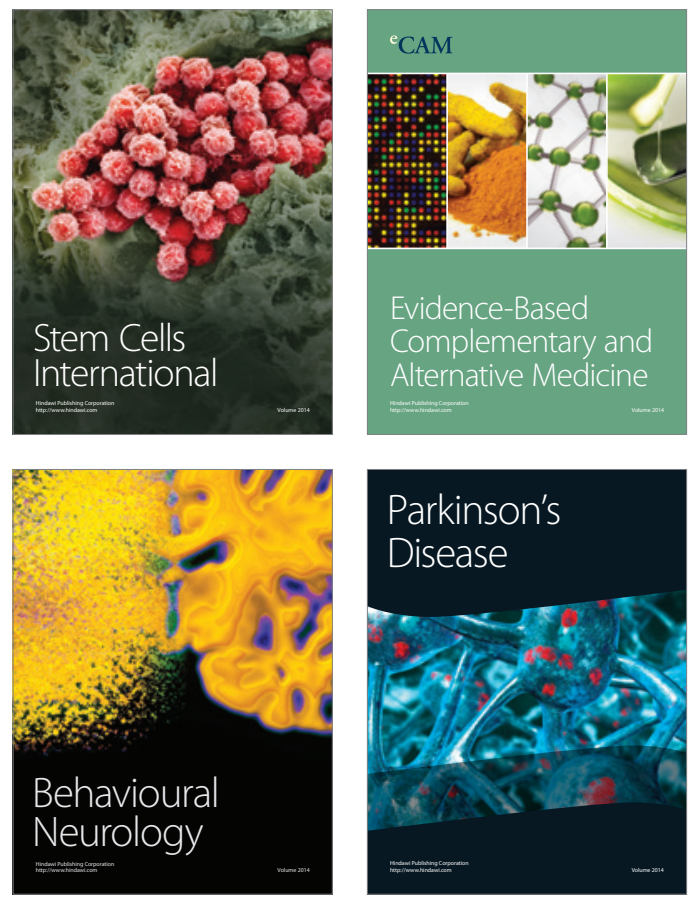
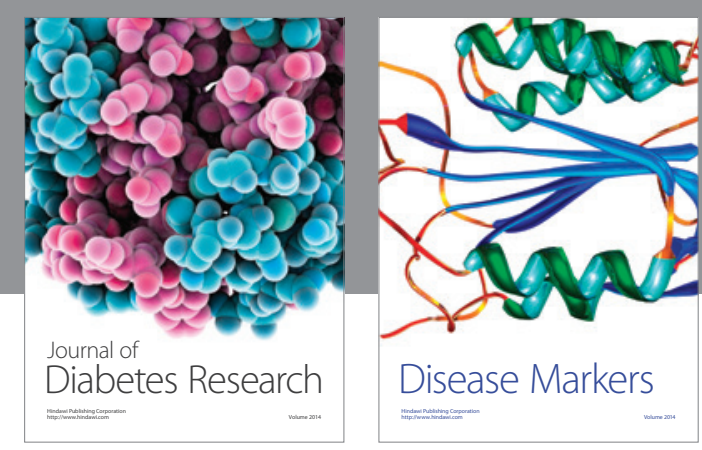

Disease Markers
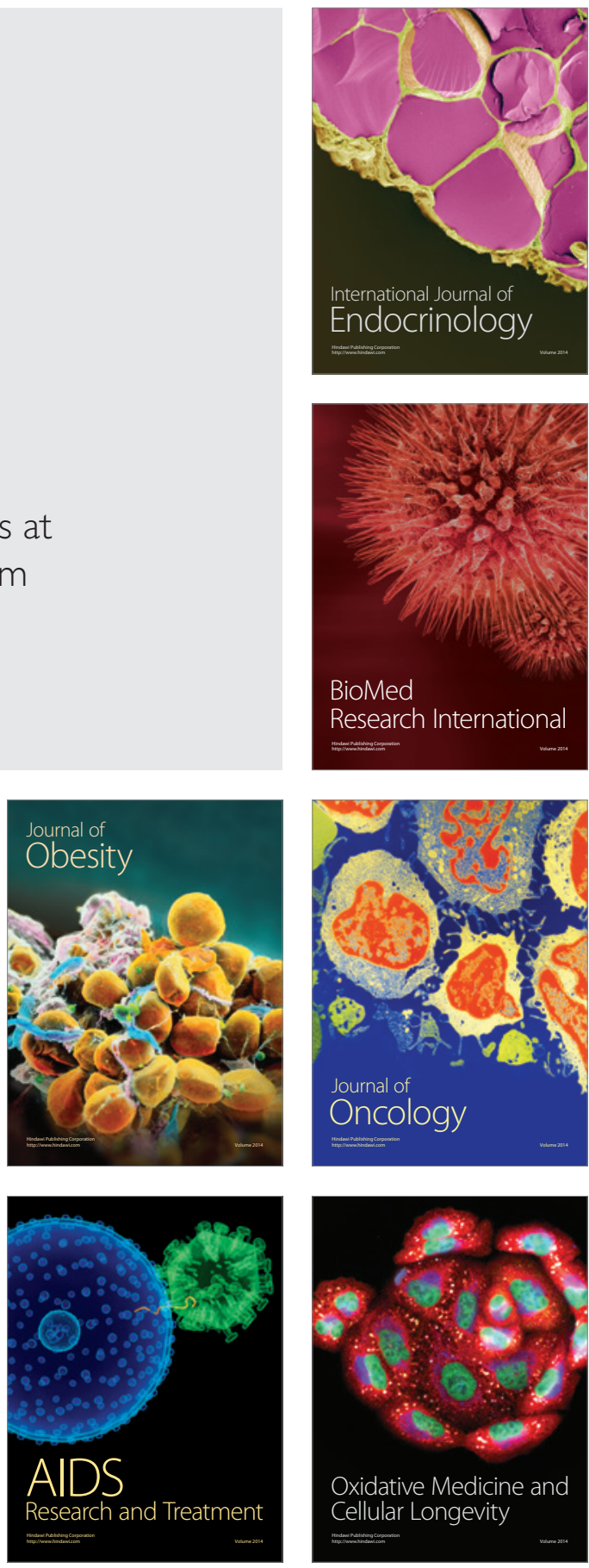